\title{
Assessment of Serum 25- Hydroxycholecalciferol Level in Patients with Recalcitrant Palmoplantar Warts
}

\author{
Noha Z. Tawfik', Hadeer I. Hussein'1, Ranya M. Hassan², and Mona A. Atwa' \\ 'Department of Dermatology and Venereology, and 'Department of Clinical Pathology, Faculty of Medicine, \\ Suez Canal University, Ismailia, Egypt
}

\begin{abstract}
Background: Viral warts are benign growths that result from an infection of epidermal or mucosal cells with the human papillomavirus. Epidemiological studies have demonstrated a link between vitamin $D$ deficiency and increased rates of infectious diseases and their resistance to treatment. Such a link between vitamin D level and wart recalcitrance is yet to be revealed. To the best of our knowledge, there were no previous studies conducted to reveal the possible relationship between vitamin $D$ and recalcitrant warts. Aim: To assess serum vitamin $D$ levels in patients with recalcitrant palmoplantar warts. Subjects and Methods: A cross-sectional study conducted on two groups. The first group included 35 patients with recalcitrant palmoplantar warts, the second group included 35 healthy volunteers matched for age, sex. Serum vitamin D level was measured. Results: A total of 78 participants were enrolled in this study, including 30 males and 48 females, distributed among the 3 groups. There was no statistically significant difference in serum vitamin $D$ levels between the studied groups. Its mean level in the recalcitrant group was $26.03 \mathrm{ng} / \mathrm{ml}$, while in the responsive group it was $29.36 \mathrm{ng} / \mathrm{ml}$ and reached $25.15 \mathrm{ng} / \mathrm{ml}$ in the control group. Conclusion: low serum vitamin D levels do not seem to increase the susceptibility of warts to get resistant to treatment.
\end{abstract}

Keywords: Warts, Recalcitrance, Serum vitamin D, Human Papilloma Virus

\section{Introduction}

Cutaneous viral warts represent a major economic and public health problem according to the 2010 Global Burden of Disease study ${ }^{(1)}$. The greatest incidence of affection occurs between 12 and 16 years of age, with the peak incidence at age 13 years in females and age 14.5 years in males $^{(2)}$. Although it is a benign condition, it has insightful appearance, tends to koebnerize, and can be transmitted to others. This makes adequate and timely treatment pivotal(3). Despite evidencebased guidelines for management of warts, a significant proportion of common warts fail to resolve, these are referred to as "recalcitrant warts". There is no consensus on a single definition of recalcitrant warts(4). However, it has been suggested to define them as those that fail to respond to one or more treatment modalities $^{(5)}$. Up to one-third of non-genital warts are expected to be recalcitrant, es- 
pecially the plantar, periungual and subungal types(5). No single satisfying explanation is there for why some warts get resistant to treatment while others respond properly. Many modalities are available for the treatment of recalcitrant multiple common warts, but none of them offer a guarantee of cure ${ }^{(6)}$. During the past decade, better understanding of vitamin D actions, that exceed its bone formation, has emerged, and there has been much interest in its potential antimicrobial role against several bacterial and viral infections $^{(7)}$. Epidemiological studies have demonstrated a link between vitamin $D$ deficiency and increased rates of infectious diseases(7-9). It is well established that topical vitamin D3 analogues have some biological actions in epidermal cells, such as regulation of cell proliferation and differentiation and modulation of their cytokine production; increasing the expression of involucrin, transglutaminase, loricrin, and filaggrin ${ }^{(10)}$. To the best of our knowledge, serum vitamin $D$ levels have not been assessed before as a possible association with recalcitrant or recurrent warts. This study plans to find out whether there is such an association thus giving us a better understanding of such intractable infections and opening the way for better future management approaches.

\section{Subjects and Methods}

A cross-sectional comparative study was carried out at the Dermatology Outpatient Clinic and clinical pathology department, Suez Canal University Teaching Hospitals, Ismailia, Egypt. An Approval was acquired from the Ethics committee. Written informed consent was taken from each participant. Patients were selected using consecutive non-probability sampling technique. The study included 3 groups: Group 1: included 19 patients with recalcitrant warts who failed to show any response to one or more standard treatment modalities (six sessions of cryotherapy with an average of one to two weeks apart $)^{5}$, Group 2: included 28 patients with responsive warts who showed response to less than 6 sessions of cryotherapy , Group 3: Included 31 patients, age and sex matched individuals as a control group. We excluded patients on vitamin $D$ supplementation or using cod-liver oil, which contains a high concentration of vitamin $D$ or receiving phototherapy, female patients who are pregnant, lactating or using oral contraceptives. Young adults with juvenile idiopathic arthritis or adults with rheumatoid arthritis or any other autoimmune or inflammatory diseases. Patients known to have malabsorption, short bowel, or cholestatic liver disease. Use of anticonvulsants, rifampicin, cholestyramine, highly active antiretroviral treatment (HAART), or glucocorticoids. All patients included in the study were subjected to full history taking,general and dermatological examination.

Assessment of serum 25- hydroxycholecalciferol level

Serum 25- hydroxycholecalciferol level was measured by vitamin D Enzyme-linked immunosorbent assay (ELISA) kit manufactured by Orgentec Diagnostika $\mathrm{GmbH}$, Germany.

Assay procedure: The determination of serum $25-\mathrm{OH}$ vitamin $\mathrm{D}$ level was based on a competitive ELISA with the following steps: The released $25-\mathrm{OH}$ vitamin D sample was transferred to reaction wells of the microtiter plate. $25-\mathrm{OH}$ vitamin $\mathrm{D}$ in the sample competed with the $25-\mathrm{OH}$ vitamin $D$ tracer reagent for binding to the $25-\mathrm{OH}$ vitamin $\mathrm{D}$ antibodies coated onto the microwells. Complexes were formed between antibody and $25-\mathrm{OH}$ vitamin $\mathrm{D}$ or antibody and $25-\mathrm{OH}$ vitamin $\mathrm{D}$ tracer. After incubation, a first washing step removed 
unbound and unspecifically bound molecules. Subsequently added enzyme conjugate bound to the immobilized tracerantibody complexes. After incubation, a second washing step removed unbound enzyme conjugate. Addition of enzyme substrate solution resulted in blue color development during incubation. Addition of an acid stopped the reaction generating a yellow end-product. The intensity of the yellow color correlated inversely with the concentration of vitamin $D$ in the sample and could be measured photometrically at 450nm.

\section{Statistical analysis}

Data was collected and coded then entered into spreadsheets using Microsoft Excel 2010 for Windows, of the Microsoft Office bundle; 2010 of Microsoft Corporation, United States. Data was analyzed using IBM Statistical Package for Social Sciences software (SPSS), $21^{\text {st }}$ edition, IBM, United States. Normally distributed continuous data was expressed as mean \pm standard deviation. Categorical data was displayed as frequency and percentage. Data was presented as tables and graphs. Kruskal Wallis test was used to compare between more than 2 not-normally distributed variables. Chi-squared test was used to compare between the qualitative data expressed as number and percentage, wherever compatible. Correlation (Spearman test) was used to identify relations between data and results were considered statistically significant at a p-value $<0.05$.

\section{Results}

A total of 78 participants were enrolled in this study, including 30 males and $48 \mathrm{fe}$ males, distributed among 3 groups: a recalcitrant to treatment group, a responsive to treatment group and a control one. Patients in both recalcitrant and responsive groups were selected from those who have palmer, planter or both palmer and planter warts. Their ages ranged between 19 and 62 years with mean of $33 \pm 11.37$. Most of the patients were of skin type IV. The most frequent occurrence per control group is skin type III. There was no statistically significant difference in serum vitamin D levels between study groups ( $p$ value $=0.471)$ with the mean level was $26.03 \pm 14.25$ (Table 1 ).

\begin{tabular}{|c|c|c|c|c|}
\hline Group & $\begin{array}{c}\text { Recalcitrant } \\
\text { Group }\end{array}$ & $\begin{array}{c}\text { Responsive } \\
\text { Group }\end{array}$ & $\begin{array}{l}\text { Control } \\
\text { Group }\end{array}$ & p-value \\
\hline Serum Vitamin D (ng/ml) & $26.03 \pm 14.25$ & $29.36 \pm 12.39$ & $25.15 \pm 14.06$ & $0.471 *$ \\
\hline Daily sunlight exposure (hrs.) & $3.25 \pm 3.37$ & $2.61 \pm 2.87$ & $2.13 \pm 1.62$ & $0.824^{*}$ \\
\hline
\end{tabular}

Patients were divided in groups according to serum vitamin D level (Table 2). There was no statistically significant difference between study groups regarding daily exposure to sunlight as shown in (Table 1). In addition, as would be expected, serum vitamin D levels went parallel with average daily sun exposure hours (figure 1).There were significant positive correla- tions between serum vitamin $D$ level and daily exposure to sun $(p=0.041)$ (Table 3$)$.

\section{Discussion}

Although what we have so far of the aforementioned facts, and to the best of our knowledge, serum vitamin $D$ level in patients with recalcitrant 
warts has not yet been estimated as a possible association with such stubborn infection. Such association if proved could open the door wide to clearer understanding of the mechanism by which such infection becomes unresponsive to treatment in some patients, and thus paving the way towards more effective management Shim and his colleagues found increased prevalence of cervi- covaginal warts among those with low levels of vitamin $\mathrm{D}^{(11)}$. That contradicts Garcia's study although they studied the same type of warts ${ }^{(12)}$. Hence, further studies were to be held. It was suggested that there may be an etiological role of vitamin $D$ deficiency and common wart infection following finding of increased prevalence of its deficiency among those affected with warts ${ }^{(13,14)}$.

\begin{tabular}{|c|c|c|c|c|c|}
\hline Group & $\begin{array}{c}\text { Resistant } \\
\mathrm{n}(\%)\end{array}$ & $\begin{array}{c}\text { Responsive } \\
\mathrm{n}(\%)\end{array}$ & $\begin{array}{c}\text { Control } \\
\mathrm{n}(\%)\end{array}$ & $\begin{array}{l}\text { Total } \\
\mathrm{n}(\%)\end{array}$ & $\mathrm{p}$-value \\
\hline Deficient & $1(5 \cdot 3)$ & $2(7.1)$ & $6(19.4)$ & $9(11.5)$ & \multirow{4}{*}{$0.242 *$} \\
\hline Insufficient & $7(36.8)$ & $5(17.9)$ & $6(19.4)$ & $18(23.1)$ & \\
\hline Sufficient & $11(57.9)$ & $21(75)$ & $19(61.3)$ & $51(65.4)$ & \\
\hline Total & $19(100)$ & $28(100)$ & $31(100)$ & $78(100)$ & \\
\hline
\end{tabular}

We found that serum vitamin D levels in patients with recalcitrant warts were generally lower than that in the control group, and its level among those responsive to treatment are in general higher than that in the control ones, which may indicate higher response rates going with higher serum levels of vitamin $D$ and vice versa. However, there was no bio-statistical significance of such variation. In other words, wart recalcitrance to treatment has no significant association with patients' serum 25hydroxycholecalciferol level. This can be explained by Autier and his col- leagues(15) who thought that the strong association between low serum vitamin $D$ levels and different inflammatory and infectious diseases was just a marker of generally ill health. The inflammatory process by itself involved in disease occurrence and clinical course would be the one accused for reducing serum vitamin $D$ levels. This would explain its low-level association with a wide array of different unrelated diseases. In other words, it may be the result and not the cause of physiological disturbances accompanying some diseases ${ }^{(15)}$.

\begin{tabular}{|l|c|c|}
\hline \multicolumn{3}{|c|}{$\begin{array}{c}\text { Table 3. Correlation between vitamin } \mathrm{D} \text { and study variables in } \\
\text { resistant, responsive and control groups. }\end{array}$} \\
\hline Variable 1 & $\rho$ & $p$-value \\
\hline Average daily sunlight exposure (hrs.) & 0.234 & $\mathbf{0 . 0 4 1 *}$ \\
\hline Number of lesions & 0.104 & $0.496^{*}$ \\
\hline Disease duration (months) & 0.217 & $0.152^{*}$ \\
\hline $\begin{array}{l}\text { Spearman correlation test; } \rho=\text { Spearman's correlation coefficient. } \\
\text { *= Statistically significant at } p \leq 0.05\end{array}$ \\
\hline
\end{tabular}




\section{Study Limitations}

A limitation to our study is that it is an observational one, and because serum vitamin $D$ level is influenced by a wide array of factors e.g. aging, latitude, adiposity, physical activity, UV light exposure, smoking, and $\operatorname{diet}^{(16)}$ that are hard to be precisely controlled, resulting in an inevitable confounding bias to our data. Most of our knowledge of vitamin $\mathrm{D}$ and its association with different diseases are based mainly on observational studies as was ours. Although intervention studies will give much yield, observational studies still carry on their shoulders a big task of unveiling vitamin $D$ secrets as randomized controlled trials still have a lot of limitations that limit their validity ${ }^{(17)}$. Furthermore, serum vitamin $D$ can be influenced by Genetic and epigenetic factors $^{(18)}$. That further disturbs the homogenization of target population among different studies, thus, biasing their results. Another limitation was the relatively small study population which might hinder extrapolation of the results. Further studies on wider scales might reveal more reliable results. Further and deeper research is needed to enlighten this area of our knowledge, and to either prove it more or decline its significance. Such findings are still recent and need more studies with larger number of included participants to reach solid ground in such new prospective of individualized wart treatment approach. This may help more homogenization of selected patients with viral warts in upcoming studies after revealing such a possible cofounding factor.

\section{Conclusion}

There was no statistically significant difference in serum vitamin D levels between the studied groups as low serum vitamin D levels do not seem to increase the susceptibility of warts to get resistant to treatment.

Funding details: All costs of this study were provided by the researchers. There were no sponsors or fund for the research

Conflict of interest: There is no conflict of interest.

Acknowledgements: we are thankful to all the participants who were very cooperative and welcoming to be part of this study. The patients in this manuscript have given written informed consent to publication of their case details.

\section{References}

1. Hay RJ, Johns NE, Williams HC, et al. The global burden of skin disease in 2010: an analysis of the prevalence and impact of skin conditions. J Invest Dermatol 2014, 134(6):1527-1534.

2. Plasencia JM. Cutaneous warts: diagnosis and treatment. Primary Care: Clinics in Office Practice 2000; 27(2): pp.423-434.

3. Thappa DM and Chiramel MJ. Evolving role of immunotherapy in the treatment of refractory warts. Indian Dermatol online J 2016; 7(5):364.

4. Leung L. Recalcitrant nongenital warts. Aust Family Physician 2011; $40(1 / 2): 40$.

5. Sethuraman G, Richards KA, Hiremagalore RN and Wagner A. Effectiveness of pulsed dye laser in the treatment of recalcitrant warts in children. Dermatologic Surg 2010; 36(1):58-65. 
6. Lipke MM. An armamentarium of wart treatments. Clin Med Res 2006; 4(4):273-293.

7. Kamen DL and Tangpricha V. Vitamin $D$ and molecular actions on the immune system: modulation of innate and autoimmunity. J Mol. Med. 2010; 88(5):441-450.

8. Jeffery, L.E., Burke, F., Mura, M., et al. 1, 25-Dihydroxyvitamin D3 and IL-2 combine to inhibit $T$ cell production of inflammatory cytokines and promote development of regulatory $T$ cells expressing CTLA-4 and FoxP3. J Immunol 2009: 183(9):5458-5467.

9. Imagawa I and Suzuki H. Successful treatment of refractory warts with topical vitamin D3 derivative (maxacalcitol, $1 a$, 25-dihydroxy-22-oxacalcitriol) in $17 \mathrm{pa}$ tients. J Dermatol 2007; 34(4):264266.

10. Korf H, Decallonne B and Mathieu C. Vitamin D for infections. Cur Opin Endocrinol, Diabetes and Obesity 2014; 21(6): 431-436.

11. Shim J, Pérez A, Symanski E, Nyitray AG. Association between serum 25hydroxyvitamin $D$ level and human papillomavirus cervicovaginal infection in women in the United States. J Infect Dis 2016; 213 (12):1886-1892.

12. Garcia-Carrasco M, Mendoza-Pinto C, Munguia-Realpozo P, et al. Lack of association between serum 25hydroxyvitamin D levels and cervical human papillomavirus infection in systemic lupus erythematosus. Lupus 2015; 24(6):606-612.

13. Öztekin C, Öztekin A, Taştan K, Özmen GG, Demir Pektaş S. The association between verruca vulgaris and Vitamin D: Is there a casual link? Acta Medica Mediterr 2018;34(4):1047-1050.

14. El Mongy NN, Hilal RF, Badr AM, Alraawi SA. Serum vitamin $D$ level in patients with viral warts. J Egy Women's Dermatol Soc 2018;15(3):133-138.

15. Autier $\mathrm{P}$, Boniol $\mathrm{M}$, Pizot $\mathrm{C}$ and Mullie P. Vitamin $D$ status and ill health: a systematic review. Lancet Diabetes Endocrinol 2014; 2: 76-89.

16. Tsiaras WG and Weinstock MA. Factors influencing vitamin D status. Acta Dermato-Venereologica 2011; 91 (2):115-124.

17. Scragg R. Limitations of vitamin D supplementation trials: Why observational studies will continue to help determine the role of vitamin $D$ in health. J Steroid Biochem Mol Biol 2018: 177:69.

18. Bahrami A, Sadeghnia HR, Tabatabaeizadeh SA, Bahrami-Taghanaki $\mathrm{H}$, Behboodi N, Esmaeili H, Ferns GA, Mobarhan MG and Avan A. Genetic and epigenetic factors influencing vitamin D status. J Cellular Physiol 2018;233(5):4033-4043. 